\title{
EDITORIAL
}

\section{Three-way interactions between plants, microbes and insects}

\author{
Arjen Biere $^{* 1}$ and Alison E. Bennett ${ }^{2}$ \\ ${ }^{1}$ Department of Terrestrial Ecology, Netherlands Institute of Ecology, NIOO-KNAW, Droevendaalsesteeg 10, 6708 PB, \\ Wageningen, The Netherlands; and ${ }^{2}$ Ecological Sciences, The James Hutton Institute, Errol Road, Invergowrie, \\ Dundee, DD2 5DA UK
}

\section{Introduction}

Plants are important mediators of interactions between their associated microbe and insect communities (Van der Putten et al. 2001; Ohgushi 2005). Changes in plants induced by one species have cascading effects on interactions with other species, shaping their abundances and community structure (Ohgushi 2008). While the consequences of such indirect interactions for community structure have predominantly been examined within the plant-associated insect community (e.g. Van Zandt \& Agrawal 2004; Poelman et al. 2008; Utsumi 2011), there is growing evidence that there are similar community-wide impacts of plant-mediated interactions between microbes and insects (e.g. Kluth, Kruess \& Tscharntke 2001; Omacini et al. 2001; Katayama, Zhang \& Ohgushi 2011; Tack, Gripenberg \& Roslin 2012). This highlights the ecological importance of three-way interactions between plants, microbes and insects. The study of such 'plant-microbeinsect' (PMI) interactions (Fig. 1) is a research area that has been rapidly expanding in the past two decades. Molecular studies of the mechanisms underlying these three-way interactions, as well as ecological and evolutionary studies of the consequences of PMI interactions in natural communities, have recently given a large impetus to this young field. In this special feature, we have brought together eight papers reviewing different aspects of these recent advances in the field of PMI interactions.

Research on PMI interactions has gradually bridged the traditionally separated subdisciplines of plant pathology, insect pathology and entomology. Plant pathologists early on realized that insects were not only important vectors of plant disease, but also one of the factors determining what was then called 'host predisposition' (Yarwood 1959; Schoeneweiss 1975). This term was used to describe any environmental alteration of the susceptibility of host plants to their pathogens, prior to their interaction. Similarly, in the 1980s, a series of reviews from entomologists appeared on the effects of plant- and insect-associated microbes on plant resource exploitation by insects (e.g. Jones 1984; Hammond \& Hardy 1988), culminating in the seminal

*Correspondence author. E-mail: a.biere@nioo.knaw.nl book on microbial mediation of plant-insect interactions by Barbosa, Krischick \& Jones 1991, which provided the first detailed and fascinating overview of the widespread, diverse and strong roles played by plant- and insect-associated microbes in shaping plant-insect interactions.

PMI interactions represent a broad research field, both in terms of the disciplines involved (from molecular
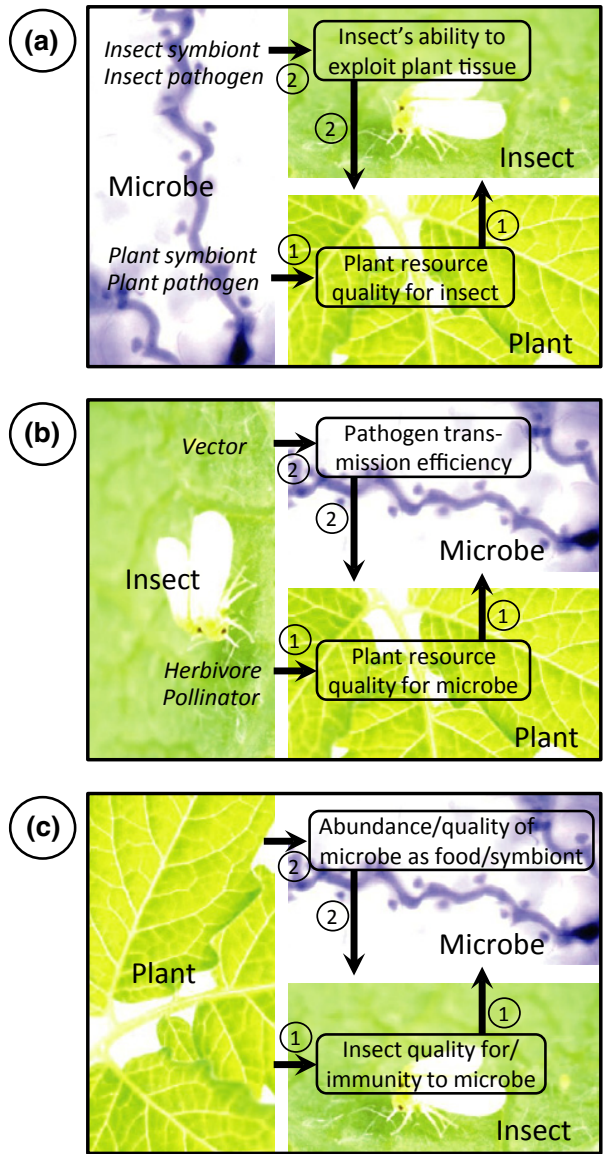

Fig. 1. Three types of three-way interactions between plants, insects and microbes: (a) examples of microbial mediation of plant-insect interactions; (b) examples of insect mediation of plant-microbe interactions; (c) examples of plant mediation of insect-microbe interactions. For further explanation, see text. Photograph credit whitefly: Tibor Bukovinszky, Bugsinthe Picture.com. 
biology to community ecology) and in terms of the diversity of types of interactions that it embodies. Microbial mediation of plant-insect interactions (Fig. 1a) is in fact just one of three ramifications of PMI interactions, illustrated in Fig. 1, that further encompass insect mediation of plant-microbe interactions (Fig. 1b) and plant mediation of insect-microbe interactions (Fig. 1c).

Microbial mediation of plant-insect interactions involves two basic pathways (Fig. 1a, arrows 1; Fig. 1a, arrows 2). First, plant microbial pathogens and symbionts affect the suitability of their host plants as a resource for herbivorous insects through alteration of their abundance, phenology, morphology, physiology, biochemistry or other aspects that subsequently affect herbivore performance, population dynamics and community structure (Fig. 1a-1; e.g. Hatcher 1995; Stout, Thaler \& Thomma 2006; Hartley \& Gange 2009; Pineda et al. 2010). One example of such interactions is the induction of defences against herbivores by some phytopathogens (Stout, Thaler \& Thomma 2006). Second (Fig. 1a-2), insect microbial pathogens and symbionts affect the ability of their insect hosts to exploit their food plants, exerting a strong influence on their performance, dynamics and specialization on different food plants (e.g. Jones 1984; Janson et al. 2008; Feldhaar 2011; Ferrari \& Vavre 2011; Frago, Dicke \& Godfray 2012). For example, acquisition of microbial nutritional endosymbionts not only enabled insects to evolve a plantsap-feeding lifestyle (Takiya et al. 2006), but also facilitates current host shifts of pest insects onto agricultural crops (e.g. Hosokawa et al. 2007). This type of interaction also includes microbial symbionts that are actively transmitted and cultivated by insects to break down plant tissue, such as the fungal gardens of leaf-cutting ants (e.g. Currie et al. 2003).

Microbial mediation of plant-insect interactions is mirrored by insect mediation of plant-microbe interactions (Fig. 1b). First (Fig. 1b-1), insects can affect the abundance, accessibility or suitability of host plant tissue for the plant's microbial symbionts and pathogens (Fig. 1b-1; e.g. Hatcher 1995; Rostás, Simon \& Hilker 2003; Stout, Thaler \& Thomma 2006). Some examples of successful biological control are based on this type of interaction. For instance, the success of the Argentine cactus moth in controlling the invasive prickly pear in Australia in the 1920s was partly based on the fact that its feeding wounds provided access to secondary pathogens that killed the cactus (Caesar 2000). Second (Fig. 1b-2), insects affect plantmicrobe interactions as vectors of plant pathogens. The far-reaching consequences of this type of interaction are evident from the knock-on effects of the introduction of disease-vectoring insects that cause severe problems in natural systems and agriculture due both to their introduction of new plant diseases and their enhanced spread of plant diseases that were already present in the area (e.g. Pan et al. 2012).

Finally (Fig. 1c), plants can significantly impact insectmicrobe interactions. For example, food plant quality can affect the susceptibility of herbivorous insects to their entomopathogens (Fig. 1c-1; Cory \& Hoover 2006; Cory \& Ericsson 2010) or affect their availability as food for, for example, mycophagous insects, as well as the performance of insect nutritional symbionts (Fig. 1c-2; e.g. Davis \& Hofstetter 2012).

Since the seminal work by Barbosa, Krischick \& Jones (1991), there has been an upsurge of research on PMI interactions, and vast progress has been made, particularly in three areas of research. First, the rise of new molecular methods has revolutionized studies on the molecular mechanisms underlying induced responses of plants to microbes and insects. This has led to detailed insight into the molecular networks underlying signalling and defence activation by plants in response to different guilds of microbes and insects. This insight has been helpful in understanding how plants integrate and prioritize their responses to multiple attackers and to understand observed patterns in the induction of resistance (or susceptibility) to particular guilds of insects by particular guilds of microbes and vice versa. Second, PMI studies are increasingly placed in a community context. Whereas initial studies mainly focused on the effects of PMI interactions at the level of the physiology or individual performance of organisms, there has been an increasing effort to place PMI interaction studies in a community-wide perspective, incorporating interactions with higher trophic levels, effects on community structure and composition and assessing their importance in the context of climate change and biological invasions. In addition, the scope has widened from a focus on phytopathogens and insect herbivores and their endosymbionts to incorporate other classes of organism, such as plant symbionts (e.g. mycorrhizae, rhizobia and endophytes) and rhizobacteria, revealing their important roles in PMI interactions. Third, there has been an increasing effort to understand the role of PMI interactions in the evolution of traits of species involved in the interaction and in eco-evolutionary feedbacks. Below, we introduce the eight papers in this special feature in the context of these new developments.

\section{Mechanisms underlying induced plant responses to microbes and insects and their consequences for plant-microbe-insect interactions}

One of the important mechanisms underlying PMI interactions is the induction of plant defences by insects and beneficial or pathogenic microbes that result in cross-resistance or susceptibility. In the past two decades, molecular biologists have made vast progress in unravelling the complex regulation of the plant's induced responses to biotic agents (e.g. Pieterse et al. 2012). This has provided valuable insight into how plants tailor their responses to specific biotic agents and in the potential patterns of cross-induced resistance and susceptibility. The contributions by Pineda et al., Giron et al., Hauser et al. and Ponzio et al. all address aspects of the mechanisms underlying induced 
plant responses and their consequences for PMI interactions. Induced responses of plants to biotic agents have a complex regulation. Its basis is formed by a network of defence signalling pathways that is regulated by a small set of phytohormones in which salicylic acid (SA), jasmonic acid (JA) and ethylene (ET) play key roles. Biotic attack triggers a specific set of signals, and their timing and composition (the 'signal signature') determine the set of downstream defence genes that is subsequently activated (Pieterse \& Dicke 2007). The general picture emerging from these studies is that there is broad overlap in the signalling pathways that are triggered by particular types of insects and microbes, but that the pattern of downstream activation of defences is highly specific for the particular plantattacker combination (De Vos et al. 2005). An important reason for this specificity in the activation of defences is that there are additional levels of regulation of the signal signature, both by the plants and by their attackers. Importantly, signalling pathways are interconnected and 'crosstalk', providing an additional level of regulation that gives plants the opportunity to fine-tune and prioritize their defence in response to specific attackers.

Pineda et al. (2013) in this issue show that this crosstalk is not restricted to signals coming from the biotic component of the environment. Signalling pathways triggered by abiotic stress interact with those triggered by microbes and insects. This results in strong effects of abiotic stress on plant-microbe, plant-insect and PMI interactions. For instance, the phytohormone abscisic acid (ABA), an important regulator of plant responses to osmotic stress imposed by drought and salt, interacts in a complex, but well understood way with SA, JA and ET. Such information is clearly relevant if we want to predict the impact of environmental change on PMI interactions. The authors provide a review of studies of the effects of abiotic stress on PMI interactions that shows an interesting pattern. In general, plant-mediated effects of microbes on herbivores are enhanced under abiotic stress. In accordance with the observed pattern, the protective effect of beneficial microbes against herbivory and their effect on tolerance to biotic and abiotic stresses appear to be enhanced under the most stressful abiotic conditions, or, as the authors put it, beneficial microbes help plants when they need it most. This raises the interesting question whether this type of crosstalk between signals from the abiotic and biotic environment has evolved as an adaptive plant mechanism, enabling them to regulate the extent to which they accommodate beneficial microbes in response to the extent of abiotic stress that they experience (cf. Thaler, Humphrey \& Whiteman 2012). Insight into these mechanisms can provide a better understanding of how the abiotic environment induces shifts between mutualism and antagonism in interactions between plants and their microbial symbionts.

Unravelling mechanisms of plant responses in biotic interactions with beneficial and harmful biotic organisms has mainly focused on the role of the plant hormones JA, SA, ET as key players in the signalling network regulating plant growth and defence. The role of other phytohormones as additional regulators in these networks has only recently become fully appreciated (Robert-Seilaniantz, Grant \& Jones 2011). Whereas the contribution by Pineda et al. (2013) that was described above highlights the importance of ABA, Giron et al. (2013) in this issue review the role of another phytohormone that is strongly underrepresented in studies of plant biotic interactions, namely cytokinins (CKs). Through their effects on source-sink relationships, senescence and plant defence, these phytohormones play an important role in plant biotic interactions. Over evolutionary time, cytokinins have become targets of modulation by microbes and arthropods as a means of controlling plant metabolism to the benefit of these pathogens and herbivores. A striking example are leaf miners that can selectively delay senescence and preserve the nutritional value of the leaf tissue that they inhabit through cytokinin-mediated modulation of the physiology of their host plants leaves. Interestingly, these cytokininmediated alterations are not mediated by the insect itself, but by one of its microbial endosymbionts. This illustrates the complexity of such PMI interaction and the role that insect endosymbionts play in expanding the ecological niche of their insect hosts. The review gives a fascinating insight into the diverse roles of cytokinins in biotic interactions and suggests that they play an important role in the regulation of complex source-sink relationships structuring plant-based food webs.

Many studies of PMI interactions have documented the consequences of plant-mediated interactions between insects and microbes for the performance of these insects and microbes, but very few have examined the consequences for the fitness of the mediating plant itself to assess how the way in which plants cope with multiple attacks affects their own performance. Hauser et al. (2013) in this issue perform a meta-analysis of the combined effects of plant pathogens and insect herbivores on plant performance. They analyse patterns of additive, synergistic and antagonistic effects of different guilds of insect herbivores and pathogens on plant performance by comparing their combined impact with their impacts as single attackers. Interestingly, molecular studies of the mechanisms underlying induced defence generate predictions as to which guilds of pathogens and herbivores are expected to synergize or antagonize each other's effects on plant fitness. For example, biotrophic pathogens and piercing or sucking insects are signalled through and affected by the same (SA-dependent) defence pathway. We could therefore expect that they will antagonize each other and hence reduce each other's negative impact on plant fitness, resulting in a less-than-additive negative impact based on the sum of their individual effects. Surprisingly, very few of these predictions were supported by the meta-analysis, suggesting that additional factors are involved in determining the joint impact of herbivores and pathogens on plant fitness. An important observation from their work is that overall, pathogens and herbivores are synergistic in their 
negative effects at the level of individual plant tissues (e.g., shoot biomass), but additive to antagonistic in their effects on whole-plant biomass, corroborating similar findings from earlier studies (Fournier et al. 2006). This strongly suggests that plants can compensate for the 'extra' loss of resources from interactions between pathogens and herbivores, so that the synergistic effects at the tissue level disappears at the level of whole-plant performance.

In addition to triggering induced direct defences in plants, insects and microbes can also affect indirect defences. The term indirect defence refers to plant traits that enhance the attraction of the natural enemies of their herbivores. Plant volatile organic compounds (VOCs) mediate interactions with various members of their associated community, including other plants, microbes, insects and natural enemies of insects (Dicke \& Baldwin 2010), and are an important mediator of indirect defence. Since plant VOC emissions are strongly altered by microbes and insects, they are one of the important plant phenotypic traits mediating community-wide PMI interactions. While effects of individual herbivores or microbes on volatile emission are well studied, we have little understanding of how patterns of volatile emissions are altered when plants are under multiple attacks. Ponzio et al. (2013) in this issue review how dual attack, either by different insect herbivores or by an insect herbivore and a phytopathogen, affects VOC emission patterns. Recent work has highlighted the importance of vector-transmitted phytopathogens as modulators of the VOC emission patterns of their host plants. VOC modulation is one of the ways in which viruses manipulate the attraction of their insect vectors and optimize their transmission even to the detriment of their host plants (Mauck, De Moraes \& Mescher 2010; Bosque-Pérez \& Eigenbrode 2011). Ponzio et al. (2013) show that in dual infestations of insects and pathogens, also non-vectored pathogens can significantly alter the pattern of volatile emission. While there are too few studies to draw general conclusion, it is interesting that the few studies available are in line with predictions from our knowledge of signalling interactions. In dual attack by a microbe and a chewing insect herbivore, a necrotrophic pathogen enhanced volatile emissions compared to insect herbivory alone, whereas a biotrophic pathogen reduced it. This is in line with predictions. Necrotrophs generally trigger JA signalling, involved in activating the production of important classes of volatiles, resulting in enhancement of herbivoreinduced volatile emission. By contrast, biotrophic pathogens are generally signalled through a SA-dependent pathway that inhibits the JA pathway, resulting in reduced emission. Such interactions have important consequences for the plant as they can enhance or impede their indirect defence. The review by Ponzio et al. (2013) therefore highlights the importance of integrating both plant-microbe and plant-insect interactions in studies of the effects of herbivore-induced plant volatiles on the community dynamics of plant-associated communities.

\section{The role of plant-microbe-insect interactions in structuring communities}

Plant-mediated interactions between herbivores can be important in structuring herbivore communities (Ohgushi 2005; Kaplan \& Denno 2007). Similarly, we can ask whether plant-mediated interactions between microbes and herbivores can structure (herbivore) communities. Until recently, consequences of plant-mediated effects of microbes on herbivores mainly focused on consequences at the level of individuals and populations. That is, studies examined the effects of microbe-induced changes in plant traits or abundance on the behaviour and performance of individual herbivores or on their population dynamics. Recently, it has become clear that such effects can scale up to the community level. For instance, below-ground microbes induce bottomup effects on above-ground insect herbivores through alteration of plant abundance, nutritional quality and defence (Van der Putten et al. 2001; Hartley \& Gange 2009), exerting significant effects on insects, both at the species (Kempel, Brandl \& Schadler 2009) and community level (Katayama, Zhang \& Ohgushi 2011). As an example, rootnodulating rhizobia cause soybean to grow larger in size, resulting in higher species richness and altered community composition of chewing and sap-feeding arthropod herbivores, as well as a higher abundance and diversity of predators at higher trophic levels (Katayama, Zhang \& Ohgushi 2011). Similarly, Omacini et al. (2001) showed that grass endophytes affect the relative abundance of two aphid species, their rate of parasitism by secondary parasitoids and the structural characteristics of the food web. In addition to plant symbionts, also plant pathogens can affect insect abundances and community composition (e.g. Kluth, Kruess \& Tscharntke 2001; van Nouhuys \& Laine 2008; Tack, Gripenberg \& Roslin 2012). Thus, the community structure of insects is not only affected by plant changes induced by herbivores, but also by plant changes induced by microbes. In this issue, Tack \& Dicke (2013) review how plant pathogens impact communities of insects at multiple spatial and temporal scales. They show that such effects may arise by a variety of mechanisms. For instance, pathogen-induced changes in plant quality that affect herbivore development time can lead to phenological mismatches with the herbivore's natural enemies, whereas pathogen-induced changes in plant quality that affect oviposition and feeding behaviour can lead to changes in the spatial distribution of herbivores at different scales with subsequent effects on the insect community. Tack \& Dicke (2013) make a plea for a community-wide perspective on pathogen-plant-insect interactions and emphasize the importance of the spatial and temporal scales of these interactions. They further note that whereas studies of plant pathogens structuring herbivore communities are now emerging, our insight into the reverse interaction, how herbivores structure pathogen communities, is still very limited. 


\section{The role of plant-microbe-insect interactions in the evolution of the interacting species}

Above, we have seen the ecological consequences of plant trait-mediated indirect effects for structuring communities. Recently, there has also been increasing interest in evolutionary consequences of such trait-mediated indirect effects (Utsumi 2011), where the biotic context of, for instance, a pathogen can alter selection and adaptation in a plant-insect interaction. In this issue, Biere \& Tack (2013) review evolutionary adaptation in PMI interactions. The community context can alter the pattern of selection that two species exert on each other's ecologically important traits. For instance, the fitness of genotypes of aphids depends on the barley genotype they infest, but the strength and even direction of this interaction are further modulated by the presence or absence of a plant growth-promoting rhizobacterium (Tétard-Jones et al. 2007). The rhizobacterium thus alters the barley's phenotype (plasticity) or phenotype distribution (through natural selection), affecting the (co-)evolutionary interactions between barley and aphid. Biere \& Tack (2013) show that in this way microbes indeed modulate selection in plant-herbivore interactions, herbivores in plant-microbe interactions and plants in herbivore-microbe interactions and argue that this has important implications for our understanding of local adaptation in species interactions. Local adaptation has usually been considered in the context of two-way (e.g. host-parasite) interactions. Parasite local adaptation means that parasite genotypes that originate from a particular host population attain higher fitness on the host genotypes from that population than parasite genotypes that originate from other host populations. However, since the phenotypes of these hosts can be strongly influenced by third parties, parasites could in fact be adapted to the specific phenotypes induced by species with which they do not even directly interact. There is now accumulating evidence for such more complex patterns of local adaptation. For instance, arthropods evolutionarily adapt to the local microbial symbionts of their host plants (Bonte et al. 2010), and insect pathogens perform better on hosts when these are feeding on the local food plant species from the population from which they originate, than when they feed on non-local food plants (Cory \& Myers 2004). Detection of local adaptation is thus likely to fail in studies that have isolated a two-way interaction from the biotic context in which the interaction evolved, that is, when these studies investigate local adaptation using phenotypes that are no longer relevant to the interaction in the local population. The authors suggest local adaptation may be commonly shaped by such more complex interactions and propose studies that incorporated a full factorial combination of local vs. nonlocal plant, microbe and insect as a challenge for the future.

One of the more intimate PMI interactions that have been relatively well studied from both an ecological and evolutionary perspective are interactions between plants, plant viruses and arthropods that vector these viruses (Blanc, Uzest \& Drucker 2011). Viruses have evolved sophisticated ways of manipulating host plants by reconfiguring their primary metabolism to enhance virus multiplication and manipulate their host plant, their vector and the plant-vector interaction to enhance their transmission. Some studies suggest evolutionary convergence of host manipulation strategies among viruses in conjunction with their transmission mode (Mauck et al. 2012). However, whereas many studies have focused on how viruses affect vector behaviour and evolution, surprisingly few have, conversely, studied how vectors affect the behaviour and evolution of plant viruses. In this issue, Gutierrez et al. (2013) provide a dual review. They first review how plant viruses affect vector physiology and behaviour to increase their chances of transmission, either directly or through modification of the host plant. Then, conversely, they review how vector behaviour affects the behaviour of viruses within the infected plant, as well as their population genetics and evolution. They show that distinct combinations of within-plant viral population structure and vector feeding behaviour exert a strong impact on virus evolution. They further illustrate one of the newly discovered ways in which viruses use and reconfigure the plant's trafficking system to deliver and concentrate their dispersal units at the exact location where vectors are feeding. This is an example of how vector-related stresses induce major switches in the behaviour of plant viruses that affect their efficiency of transmission by insect vectors, illustrating a type of PMI interaction in which a plant-insect molecular dialogue changes the behaviour of a microbe.

\section{Conclusions and outlook}

The papers in this issue highlight the ecological and evolutionary importance of three-way interactions between plants, microbes and insects. Through plant-mediated effects, microbes can structure insect communities and, perhaps, insects can structure microbial communities. In turn, the community of microbes can affect selection between plants and insects. This can give rise to strong eco-evolutionary feedbacks (Post \& Palkovacs 2009). Ecoevolutionary feedback is a continuous process in which the community context drives evolutionary change in organismal traits, and these evolutionary changes in turn drive changes in ecological interactions and community structure. While there is growing evidence for such eco-evolutionary feedbacks within plant-based insect communities (Utsumi 2011), the papers in this issue show that there is ample opportunity for such feedbacks in interactions between plants, microbes and insects as well.

The papers also highlight some of the vast progress in unravelling the molecular mechanisms underlying plant responses to beneficial and pathogenic microbes and insects and their modulation by the abiotic environment. Such insight is important for understanding how plants prioritize their defence responses and cope with multiple stress, but also for understanding patterns of cross-induced resistance and susceptibility between microbes and insects, 
and for predicting how PMI interactions will respond to environmental change.

Besides their ecological and evolutionary implications, PMI interactions also have implications for fields of economic importance such as agriculture, biological invasions and conservation. There are several types of interactions between microbes and insects that have synergistic negative effects on plant performance. Such interactions can have devastating effects on crop yields, but positive effects in programmes of biological control. By contrast, there are also several types of interactions that can improve plant production, for example, by applying beneficial growthpromoting plant microbes that enhance plant resistance and tolerance to pest species and other stresses. This indicates that there are good opportunities for manipulating PMI interactions to promote crop yields and food security, which have received relatively little attention in comparison with the management of two-way interactions. One of the important implications of PMI interactions in an ecological as well as economic context is their role in biological invasions. This role is analysed in the final contribution of this issue by Bennett (2013). Due to species introductions and climate-driven range shifts, communities disassemble and reassemble, continuously creating novel combinations of plants, microbes and insects. Many hypotheses that try to explain the success or failure of plant and animal invasions are based on altered biotic interactions (Catford, Jansson \& Nilsson 2009). These usually consider two-way interactions (plant-herbivore, plant-pathogen, plant-microbial mutualist interactions, etc.). Little is known about how the increased number of more complex novel species interactions (between plants, microbes and insects) affect invasion success. In this issue, Bennett (2013) reviews whether novel PMI interactions play a role in promoting or inhibiting the spread of invasive species. In many cases, novel PMI interactions appear to promote invasive species via unpredicted non-additive interactions. The majority of cases in which PMI interactions limit invasive species are predominantly deliberate efforts of biocontrol that incidentally appear to involve more complex interactions. As a result, ignoring the influence of PMI interactions in the promotion of invasive plants, insects and microbes could have significant consequences for our ability to monitor and manage invaders.

Overall, the contributions in this issue give a detailed insight into the mechanisms and ecological and evolutionary roles of PMI interactions, which we hope will inspire the readers to join this young, developing interdisciplinary field.

\section{Acknowledgements}

We are very grateful to Charles Fox for his enthusiasm and support for this special feature and to Liz Baker and Jennifer Meyer for their editorial guidance. We thank the European Science Foundation for supporting an exploratory workshop on plant-microbe-insect interactions (organized by Arjen Biere, Sue Hartley, Thure Hauser and Tamara van Mölken) and all the participants for their inspiring contributions that formed the basis for this special feature. AEB was supported by RESAS WP 1.1 and 3.3.

\section{References}

Barbosa, P., Krischick, V.A. \& Jones, C.G. (1991) Microbial Mediation of Plant-Herbivore Interactions. John Wiley and Sons, New York, USA.

Bennett, A.E. (2013) Can plant-microbe-insect interactions enhance or inhibit the spread of invasive species? Functional Ecology, 27, 661-671.

Biere, A. \& Tack, A.J.M. (2013) Evolutionary adaptation in three-way interactions between plants, microbes and arthropods. Functional Ecology, 27, 646-660.

Blanc, S., Uzest, M. \& Drucker, M. (2011) New research horizons in vector-transmission of plant viruses. Current Opinion in Microbiology, 14, 483-491.

Bonte, D., De Roissart, A., Vandegehuchte, M.L., Ballhorn, D.J., Van Leeuwen, T. \& de la Peña, E. (2010) Local adaptation of aboveground herbivores towards plant phenotypes induced by soil biota. PLOS ONE, 5, e11174.

Bosque-Pérez, N.A. \& Eigenbrode, S.D. (2011) The influence of virusinduced changes in plants on aphid vectors: Insights from luteovirus pathosystems. Virus Research, 159, 201-205.

Caesar, A.J. (2000) Insect-pathogen synergisms are the foundation of weed biocontrol. Proceedings of the X International Symposium on Biocontrol of Weeds (ed. N.R. Spencer), pp. 793-798. Montana State University, Bozeman, MT.

Catford, J.A., Jansson, R. \& Nilsson, C. (2009) Reducing redundancy in invasion ecology by integrating hypotheses into a single theoretical framework. Diversity and Distributions, 15, 22-40.

Cory, J.S. \& Ericsson, J.D. (2010) Fungal entomopathogens in a tritrophic context. BioControl, 55, 75-88.

Cory, J.S. \& Hoover, K. (2006) Plant-mediated effects in insect-pathogen interactions. Trends in Ecology \& Evolution, 21, 278-286.

Cory, J.S. \& Myers, J.H. (2004) Adaptation in an insect host-plant pathogen interaction. Ecology Letters, 7, 632-639.

Currie, C.R., Wong, B., Stuart, A.E., Schultz, T.R., Rehner, S.A., Mueller, U.G., Sung, G.H., Spatafora, J.W. \& Straus, N.A. (2003) Ancient tripartite coevolution in the attine ant-microbe symbiosis. Science, 299, 386-388.

Davis, T.S. \& Hofstetter, R.W. (2012) Plant secondary chemistry mediates the performance of a nutritional symbiont associated with a tree-killing herbivore. Ecology, 93, 421-429.

De Vos, M., Van Oosten, V.R., Van Poecke, R.M.P., Van Pelt, J.A., Pozo, M.J., Mueller, M.J., Buchala, A.J., Metraux, J.P., Van Loon, L.C., Dicke, M. \& Pieterse, C.M.J. (2005) Signal signature and transcriptome changes of Arabidopsis during pathogen and insect attack. Molecular Plant-Microbe Interactions, 18, 923-937.

Dicke, M. \& Baldwin, I.T. (2010) The evolutionary context for herbivoreinduced plant volatiles: beyond the 'cry for help'. Trends in Plant Science, 15, 167-175.

Feldhaar, H. (2011) Bacterial symbionts as mediators of ecologically important traits of insect hosts. Ecological Entomology, 36, 533-543.

Ferrari, J. \& Vavre, F. (2011) Bacterial symbionts in insects or the story of communities affecting communities. Philosophical Transactions of the Royal Society B-Biological Sciences, 366, 1389-1400.

Fournier, V., Rosenheim, J.A., Brodeur, J., Diez, J.M. \& Johnson, M.W. (2006) Multiple plant exploiters on a shared host: testing for nonadditive effects on plant performance. Ecological Applications, 16, 2382-2398.

Frago, E., Dicke, M. \& Godfray, H.C.J. (2012) Insect symbionts as hidden players in insect-plant interactions. Trends in Ecology \& Evolution, 27, $705-711$.

Giron, D., Frago, E., Glevarec, G., Pieterse, C.M.J. \& Dicke, M. (2013) Cytokinins as key regulators in plant-microbe-insect interactions: connecting plant growth and defence. Functional Ecology, 27, 599-609.

Gutierrez, S., Michalakis, Y., Van Munster, M. \& Blanc, S. (2013) Plantfeeding by insect vectors can affect life cycle, population genetics and evolution of plant viruses. Functional Ecology, 27, 610-622.

Hammond, A.M. \& Hardy, T.N. (1988) Quality of diseased plants as hosts for insects. Plant Stress - Insect Interactions (ed. E.A. Heinrichs), pp. 381-432. John Wiley and Sons, New York.

Hartley, S.E. \& Gange, A.C. (2009) Impacts of plant symbiotic fungi on insect herbivores: mutualism in a multitrophic context. Annual Review of Entomology, 54, 323-342.

Hatcher, P.E. (1995) 3-Way interactions between plant-pathogenic fungi, herbivorous insects and their host plants. Biological Reviews, 70, 639-694.

Hauser, T.P., Christensen, S., Heimes, C. \& Kiaer, L.P. (2013) Combined effects of arthropod herbivores and phytopathogens on plant performance. Functional Ecology, 27, 623-632. 
Hosokawa, T., Kikuchi, Y., Shimada, M. \& Fukatsu, T. (2007) Obligate symbiont involved in pest status of host insect. Proceedings of the Royal Society B-Biological Sciences, 274, 1979-1984.

Janson, E.M., Stireman, J.O., Singer, M.S. \& Abbot, P. (2008) Phytophagous insect-microbe mutualisms and adaptive evolutionary diversification. Evolution, 62, 997-1012.

Jones, C.G. (1984) Microorganisms as mediators of plant resource exploitation by insect herbivores. A New Ecology (eds P.W. Price, C.N. Slobodchikoff \& W.S. Gaud), pp. 53-99. John Wiley and Sons, New York.

Kaplan, I. \& Denno, R.F. (2007) Interspecific interactions in phytophagous insects revisited: a quantitative assessment of competition theory. Ecology Letters, 10, 977-994.

Katayama, N., Zhang, Z.Q. \& Ohgushi, T. (2011) Community-wide effects of below-ground rhizobia on above-ground arthropods. Ecological Entomology, 36, 43-51.

Kempel, A., Brandl, R. \& Schadler, M. (2009) Symbiotic soil microorganisms as players in aboveground plant-herbivore interactions - the role of rhizobia. Oikos, 118, 634-640.

Kluth, S., Kruess, A. \& Tscharntke, T. (2001) Interactions between the rust fungus Puccinia punctiformis and ectophagous and endophagous insects on creeping thistle. Journal of Applied Ecology, 38, 548-556.

Mauck, K.E., De Moraes, C.M. \& Mescher, M.C. (2010) Deceptive chemical signals induced by a plant virus attract insect vectors to inferior hosts. Proceedings of the National Academy of Sciences of the United States of America, 107, 3600-3605.

Mauck, K., Bosque-Pérez, N.A., Eigenbrode, S.D., De Moraes, C.M. \& Mescher, M.C. (2012) Transmission mechanisms shape pathogen effects on host-vector interactions: evidence from plant viruses. Functional Ecology, 26, 1162-1175.

van Nouhuys, S. \& Laine, A.L. (2008) Population dynamics and sex ratio of a parasitoid altered by fungal-infected diet of host butterfly. Proceedings of the Royal Society B-Biological Sciences, 275, 787-795.

Ohgushi, T. (2005) Indirect interaction webs: herbivore-induced effects through trait change in plants. Annual Review of Ecology, Evolution, and Systematics, 36, 81-105.

Ohgushi, T. (2008) Herbivore-induced indirect interaction webs on terrestrial plants: the importance of non-trophic, indirect, and facilitative interactions. Entomologia Experimentalis et Applicata, 128, 217-229.

Omacini, M., Chaneton, E.J., Ghersa, C.M. \& Muller, C.B. (2001) Symbiotic fungal endophytes control insect host-parasite interaction webs. Nature, 409, 78-81.

Pan, H.P., Chu, D., Yan, W.Q., Su, Q., Liu, B.M., Wang, S.L., Wu, Q.J., Xie, W., Jiao, X.G., Li, R.M., Yang, N.N., Yang, X., Xu, B.Y., Brown, J.K., Zhou, X.G. \& Zhang, Y.J. (2012) Rapid spread of Tomato Yellow Leaf Curl Virus in China is aided differentially by two invasive whiteflies. PLOS ONE, 7, e34817.

Pieterse, C.M.J. \& Dicke, M. (2007) Plant interactions with microbes and insects: from molecular mechanisms to ecology. Trends in Plant Science, 12, 564-569.

Pieterse, C.M.J., Van der Does, D., Zamioudis, C., Leon-Reyes, A. \& Van Wees, S.C.M. (2012) Hormonal modulation of plant immunity. Annual Review of Cell and Developmental Biology, 28, 489-521.

Pineda, A., Zheng, S.J., van Loon, J.J.A., Pieterse, C.M.J. \& Dicke, M. (2010) Helping plants to deal with insects: the role of beneficial soilborne microbes. Trends in Plant Science, 15, 507-514.
Pineda, A., Dicke, M., Pieterse, C.M.J. \& Pozo, M.J. (2013) Beneficial microbes in a changing environment: are they always helping plants to deal with insects? Functional Ecology, 27, 574-586.

Poelman, E.H., Broekgaarden, C., Van Loon, J.J.A. \& Dicke, M. (2008) Early season herbivore differentially affects plant defence responses to subsequently colonizing herbivores and their abundance in the field. Molecular Ecology, 17, 3352-3365.

Ponzio, C., Gols, R., Pieterse, C.M.J. \& Dicke, M. (2013) Ecological and phytohormonal aspects of plant volatile emission in response to single and dual infestations with herbivores and phytopathogens. Functional Ecology, 27, 587-598

Post, D.M. \& Palkovacs, E.P. (2009) Eco-evolutionary feedbacks in community and ecosystem ecology: interactions between the ecological theatre and the evolutionary play. Philosophical Transactions of the Royal Society B-Biological Sciences, 364, 1629-1640.

Robert-Seilaniantz, A., Grant, M. \& Jones, J.D.G. (2011) Hormone crosstalk in plant disease and defense: more than just Jasmonate-Salicylate antagonism. Annual Review of Phytopathology, 49, 317-343.

Rostás, M., Simon, M. \& Hilker, M. (2003) Ecological cross-effects of induced plant responses towards herbivores and phytopathogenic fungi. Basic and Applied Ecology, 4, 43-62.

Schoeneweiss, D.F. (1975) Predisposition, stress and plant disease. Annual Review of Phytopathology, 13, 193-211.

Stout, M.J., Thaler, J.S. \& Thomma, B.P.H.J. (2006) Plant-mediated interactions between pathogenic microorganisms and herbivorous arthropods. Annual Review of Entomology, 51, 663-689.

Tack, A.J.M. \& Dicke, M. (2013) Plant pathogens structure arthropod communities across multiple spatial and temporal scales. Functional Ecology, 27, 633-645.

Tack, A.J.M., Gripenberg, S. \& Roslin, T. (2012) Cross-kingdom interactions matter: fungal-mediated interactions structure an insect community on oak. Ecology Letters, 15, 177-185.

Takiya, D.M., Tran, P.L., Dietrich, C.H. \& Moran, N.A. (2006) Co-cladogenesis spanning three phyla: leafhoppers (Insecta: Hemiptera: Cicadellidae) and their dual bacterial symbionts. Molecular Ecology, 15, 4175-4191.

Tétard-Jones, C., Kertesz, M.A., Gallois, P. \& Preziosi, R.F. (2007) Genotype-by-genotype interactions modified by a third species in a plantinsect system. American Naturalist, 170, 492-499.

Thaler, J.S., Humphrey, P.T. \& Whiteman, N.K. (2012) Evolution of jasmonate and salicylate signal crosstalk. Trends in Plant Science, 17, 260-270.

Utsumi, S. (2011) Eco-evolutionary dynamics in herbivorous insect communities mediated by induced plant responses. Population Ecology, 53, 23-34.

Van der Putten, W.H., Vet, L.E.M., Harvey, J.A. \& Wackers, F.L. (2001) Linking above- and belowground multitrophic interactions of plants, herbivores, pathogens, and their antagonists. Trends in Ecology \& Evolution, 16, 547-554.

Van Zandt, P.A. \& Agrawal, A.A. (2004) Community-wide impacts of herbivore-induced plant responses in milkweed (Asclepias syriaca). Ecology, 85, 2616-2629.

Yarwood, C.E. (1959) Predisposition. Plant Pathology (eds J.G. Horsfall \& A.E. Dimond), pp. 521-562. Academic Press, New York.

Received 6 March 2013; accepted 13 March 2013

Handling Editor: Charles Fox 